\title{
Impact of Electric Vehicle Loads on the System Load Profile of Sri Lanka
}

\author{
R.M.G.D. Ranathunga and Lalith A. Samaliarachchi
}

\begin{abstract}
Electric vehicles (EVs) are being promoted worldwide because of the potential they have to address atmospheric pollution issues and relieve countries from the burdens associated with the use of liquid petroleum based transport fuels. Ever increasing environmental concerns, improvements to battery technologies, entry of new manufacturers and new vehicle models, and introduction of favourable fiscal policies have all contributed to the increase in EV penetration rates worldwide including Sri Lanka. However, it is not clear how the power system in Sri Lanka would face the challenge of this new and unknown demand which would get added to the already exiting demand profile and which would be a result of the stochastic nature of the battery charging behaviour of EVs. In this research study, EV charging modes and charger types available in the market were considered and a model was established to ascertain the relationship between the charging demand and the other contributory factors such as EV battery sizes, charge remaining at the commencement of recharging, charging rates at different places of the chronological load profile, charging habits of customers and time-of-use pricing (TOU) policies. The probability distribution of variables such as the time of commencement of charging and battery charge duration was considered at a significantly acceptable level. By combining the probability distribution curves of the said variables, several EV charge demand curves were established using Monte Carlo method and the charging demand curves were subsequently superimposed on the system load profile. While the proposed methodology gives an insight into the impact of the EV load on the system load profile, it also shows how an effective control of EV charging could bring down the operational costs and investment cost of a power system.
\end{abstract}

Keywords: Electric vehicle, charging demand, load profile, Monte Carlo simulation

\section{Introduction}

\section{$1.1 \quad$ Background}

Because of the emphasis placed on low carbon emissions and the advantages of electricity when used in transport in place of liquid fuels, the development of EVs is being promoted in the transport sector at an accelerated pace. Compared to other electrical loads, EV loads have the ability to play a better role in load shifting and valley filling in the system load profile.

With the increasing EV population, the evaluation of the impact of aggregated EV loads with associated battery charging characteristics on the system load profile becomes important. The factors influencing the charging characteristics can be categorized as internal and external [1].

Internal factors include EV battery size, charging rates that differ depending on the amount of battery charge remaining at the commencement of charging, geographical distribution of the charging infrastructure and charging habits. The only factor that can be considered as external is the time-of-use (TOU) pricing of electrical energy. The charging behaviours of EVs have their own randomness and intermittency and their impact on the power system is high, especially when all EV users start charging their batteries at the same time during low tariff and peak load hours, requiring more power from the grid to balance the resulting increase in the generation and operation costs. Thus, there will be a growing demand for balancing measures such as the introduction of power plants for unprecedented peak loads and storage systems or demand response measures [1].

Since the EV charging load is controllable, by studying it and controlling the charging process, it would be possible to considerably improve the security and economy of power system operations. EVs would be a very attractive option for the transportation industry in Sri Lanka due to the nature of its daily load curve pattern which is skewed towards night with a high peak value.

Mrs. R.M.G.D. Ranathunga, B. Tech. Eng, Open University of Sri Lanka. Email: gdranathunga@gmail.com. Eng. Lalith A. Samaliarachchi, C.Eng, MIE(Sri Lanka), B.Sc. Eng. (Hons) (Moratuwa), M. Eng.(AIT), MIEE(UK), Senior Lecturer, Department of Electrical \& Computer Engineering, Open University of Sri Lanka. Email:lasam@ou.ac.lk 


\subsection{Types of Electric Vehicles}

EVs require highly efficient rechargeable battery packs. The electric motor installed inside an EV replaces the internal combustion (IC) engine of a conventional vehicle. The energy storage capacity of an EV is almost equivalent to the energy stored in the fuel tank of a conventional vehicle. There are two main types of EVs [1,10] available in the market, namely:

\section{- Plug in Electric Vehicle (PEV) \\ - Plug in Hybrid Electric Vehicle (PHEV)}

\subsubsection{Plug in Electric Vehicle (PEV)}

A PEV uses only electricity for propulsion. The cost of operation of PEVs is much lower than that of conventional IC engines because of their higher energy efficiency [1]. Also, it has a great potential to reduce city pollution with zero emissions and low noise.

\subsubsection{Plug in Hybrid Electric Vehicle (PHEV)}

A PHEV can store a significant amount of energy within an on-board battery for use during daily driving and the battery can be recharged from the electric grid as and when required. PHEVs have IC engines that can be used for propulsion when the battery is depleted and when higher acceleration is required and this will increase the near-term marketability of PHEVs [2].

This research study was focused on PEVs because of their economic and technological impacts.

\subsubsection{PEV Characteristics}

PEVs have several characteristics which differ from those of IC engine vehicles, and can be categorised according to their economic and technological impacts:

Economic Impacts [2]: Without any economic benefits, customers would not opt to buy PEVs because of their higher investment cost and low convenience due to their long charging times. When there are substantial tax credits for PEVs, the latter become more attractive and consequently, a higher penetration rate of PEVs could be expected.

Technological Impacts [2]: The average daily commute distance in Sri Lanka can be assumed to be around $50 \mathrm{~km}$ for each EV (at a $50 \%$ charge level), which could be translated into an energy consumption of about $12 \mathrm{kWh}$. By integrating EVs, the total demand on the power system will increase especially during the night peak, which will lead to a higher current flow in the network, thereby creating higher transmission and distribution losses. Electricity generation will also incur higher incremental costs and hence the system as a whole may also incur larger operating costs.

\subsection{Electrical Vehicle Chargers}

An EV battery can be charged at different power levels, namely from level-1(L1) to level3(L3). L1 and L2 charging are considered as slow charging and fast charging respectively, and are common in residential households [4, 9]. Level- 3 is considered as fast direct current charging (CHAdeMO/Combo) which is typically used in public areas because of its high power requirement and high installation cost. With a standard electric cable, an EV can be plugged in to a standard electric outlet to charge the battery at L1. However, L2 and L3 charging require additional equipment. Therefore, L1 seems to be more attractive since it does not require additional investment. Charging times will depend on both the capacity of the charger and the EV battery [4], which as shown in Table 1 will vary depending on the model of the car.

Table 1 - Charger Level Classifications

\begin{tabular}{|c|c|c|c|c|c|}
\hline \multicolumn{2}{|c|}{$\begin{array}{l}\text { Charging } \\
\text { mode }\end{array}$} & $\begin{array}{c}\text { Charging } \\
\text { type }\end{array}$ & $\begin{array}{l}\text { Rated } \\
\text { current }\end{array}$ & Load & $\begin{array}{c}\text { Charging } \\
\text { time }\end{array}$ \\
\hline \multicolumn{2}{|c|}{$\begin{array}{c}\text { L1 } \\
\text { Slow charging } \\
\text { Household }\end{array}$} & Single Phase & $13 \mathrm{~A}$ & \begin{tabular}{|c|} 
Up to \\
3 \\
$k W$
\end{tabular} & 6-8 Hours \\
\hline \multicolumn{2}{|c|}{$\begin{array}{c}\text { L2 } \\
\text { Fast charging } \\
\text { Household + Works+ } \\
\text { Shopping malls } \\
\end{array}$} & $\begin{array}{l}\text { Single phase } \\
\text { or } \\
\text { three Phase }\end{array}$ & $32 \mathrm{~A}$ & $\begin{array}{l}\text { Up to } \\
7-22 \\
\mathrm{~kW} \\
\end{array}$ & 3-4 Hours \\
\hline \multirow{2}{*}{$\begin{array}{c}\text { L3 } \\
\text { (Rapid } \\
\text { charging) } \\
\text { Recharging } \\
\text { station }\end{array}$} & $\begin{array}{c}\mathrm{AC} \\
\text { charging }\end{array}$ & Three phase & $63 \mathrm{~A}$ & \begin{tabular}{|c|} 
Up to \\
43 \\
$k W$ \\
\end{tabular} & $\begin{array}{c}30-60 \mathrm{~min} \\
80 \% \\
\text { Charging }\end{array}$ \\
\hline & $\begin{array}{c}\text { DC } \\
\text { charging }\end{array}$ & Three phase & $125 \mathrm{~A}$ & \begin{tabular}{|c|} 
Up to \\
43 \\
$k W$
\end{tabular} & $\begin{array}{c}30 \mathrm{~min} \\
80 \% \\
\text { Charging }\end{array}$ \\
\hline
\end{tabular}

\subsection{Aim and Objectives}

The aim of this research was to investigate, develop and apply a reasonably acceptable mathematical model for the prediction of the envisaged EV loads and to study the impact of same on the chronological load profile of the power system in Sri Lanka [3]. The objectives were:

- to identify and evaluate factors that impact on the power system because of the aggregated EV loads and

o to establish a model to capture the combined effect of EV charging loads on the system load profile. 


\section{Methodology}

The EV battery charging process is subject to uncertainties such as charging schedule, location preference and energy requirement, which complicate the charging scenario. These effects result in an uncertain total demand pattern which has to be catered to by the utility since PEV owners charge their vehicles in an unpredictable manner [2, 3, and 8]. Therefore, the random variables that are to be identified and considered would be:

- battery charging time (plug in time)

- battery charge duration

- battery state of charge

- charging mode (L1, L2 or L3)

- number of EVs

Given the circumstances, Monte Carlo simulation method will be well-suited to calculate the probabilities of the events of deterministic systems with random inputs. It will especially be useful when the system consists of more than one random variable [2]. The generic algorithm of the Monte Carlo simulation is as follows:

- Determine the random variables

- Generate random numbers for each random variable

- Process the deterministic system using all of the random variables

There is no standard structure for the Monte Carlo simulation because of its dependency on the problem. A flow chart that describes the structure of this study is shown in Figure 1 [2, 10]. The first step is to initialize the following two types of parameters:

a. EV Parameters

- Number of EVs and their charge preferences and locations with respect to the time of day

- Charging power

○ Battery capacity (kWh)

b. System Network Parameters

- Source voltage V

- Standard deviation of the load variation

For each trial, the assumed arrival time (plug in time) and battery state of charge (charge duration) were considered; and this allowed for the computing of the charge profile for each EV and for the whole day. By combining the probability distribution curves of EVs' plug in time, battery charging duration and the number of times of EV charging, demand curves were developed and superimposed on the system load profile.

\subsection{Data Processing and Initialization}

The first step of the simulation was to arrange the data properly and initialize the required parameters. The information about the behaviour of the EV drivers was included as the 'data set of drivers'.

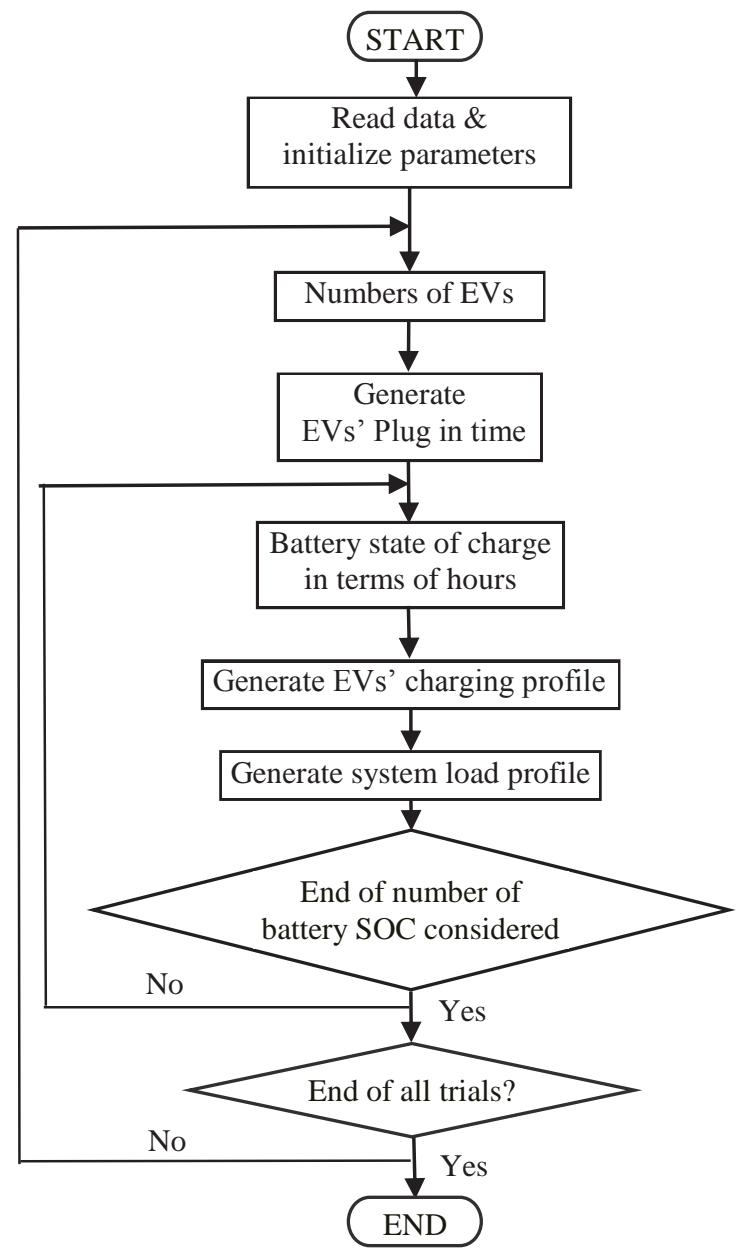

Figure 1 - Flow chart

The information about the behaviour of the EV drivers had to be assumed since a realistic data set was not readily available.

\subsection{Existing EV Usage in Sri Lanka}

The details of EV usage in Sri Lanka obtained from the Motor Traffic Department are shown in Table 2. 
Table 2 - Electric Vehicle Data 2012-2016

\begin{tabular}{|c|c|c|c|c|c|c|c|}
\hline $\begin{array}{l}\text { Brand } \\
\text { Name }\end{array}$ & $\begin{array}{c}\text { electric } \\
\text { motor } \\
\text { capacity } \\
(\mathrm{kW})\end{array}$ & \begin{tabular}{|c|} 
Battery \\
capacity \\
$(\mathrm{kWh})$
\end{tabular} & 2012 & 2013 & 2014 & 2015 & 2016 \\
\hline $\begin{array}{c}\text { NISSAN } \\
\text { (ZAA-ZEO) }\end{array}$ & 80 & 24 & 1 & 6 & 29 & 03 & 00 \\
\hline $\begin{array}{c}\text { NISSAN } \\
\text { (LEAF) }\end{array}$ & 80 & 24 & - & 3 & 35 & 684 & 189 \\
\hline $\begin{array}{c}\text { NISSAN } \\
\text { (ZAA-ZEO) }\end{array}$ & 70 & 22 & - & 2 & 15 & 86 & 2 \\
\hline $\begin{array}{r}\text { NISSAN } \\
(\text { LEAF) }\end{array}$ & 70 & 22 & - & 1 & 19 & 2275 & 648 \\
\hline $\begin{array}{c}\text { MITSUBISHI } \\
\text { (i-MiEV) }\end{array}$ & 25 & 16 & - & 1 & 2 & 59 & 19 \\
\hline *Other vehicles & & & & & & 71 & 64 \\
\hline Total & & & 1 & 13 & 100 & 3178 & 922 \\
\hline
\end{tabular}

\subsection{Arrival Times of PEVs}

The charging preferences of $\mathrm{EV}$ drivers are practically uncontrollable which means that EV drivers will try to charge their vehicles at any time at their own convenience [5].

In this study, two cases were studied in order to enable the comparison of the impacts. In one case, it was assumed that EV drivers would start charging their vehicles when they arrive home at $1900 \mathrm{hrs}$ near peak time and in the other case, it was assumed that they will start charging their vehicles at $2230 \mathrm{hrs}$. which was during off peak hours.

\subsection{Random Number Generation for the Probability Distribution}

As described below, a set of uniformly distributed random numbers was generated for the EVs with a given probability distribution for the EV plug in time and EV charge duration.

- Generation of a set of uniformly distributed random EV numbers for two EV mean plug in times (Probability density curve of Time (24 hrs.) vs. No. of EVs).

Two plug in times were considered with two different tariff structures for a better comparison since the Public Utilities Commission of Sri Lanka (PUCSL) had introduced a new optional tariff structure with effect from 10 $10^{\text {th }}$ September 2015.

The two tariff structures used were with and without time-of-use (TOU) tariff (worst case scenario). The total number of EVs taken to observe the sensitivity of the growing impact were 1000, 3000, 5000, 10000, 25000, 50000, and 100000 .
- Without TOU:

The mean plug in time was assumed to be 1900 hrs. $(\mu=1900 \mathrm{hrs}$. and $\sigma=1.67 \mathrm{hrs}$. $)$ as shown in Figure 2a

- With Time of use tariff (TOU):

The mean plug in time was assumed to be 2230 hrs. ( $\mu=2230 \mathrm{hrs}$. and $\mathrm{o}=0.5 \mathrm{hrs}$.) as shown in Figure 2b

The standard deviation of the random number distribution is as per $99.7 \%$ confidence level of the standard normal distribution.

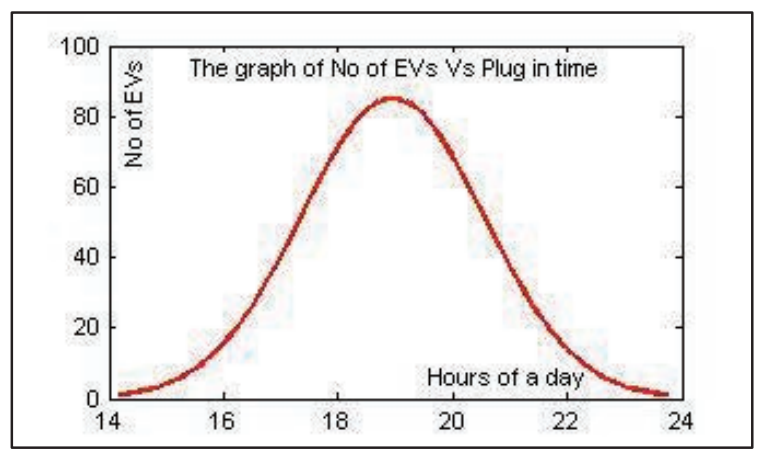

Figure 2a - Graph of No. of EVs without TOU $(\mu=1900$ and $\sigma=1.67)$

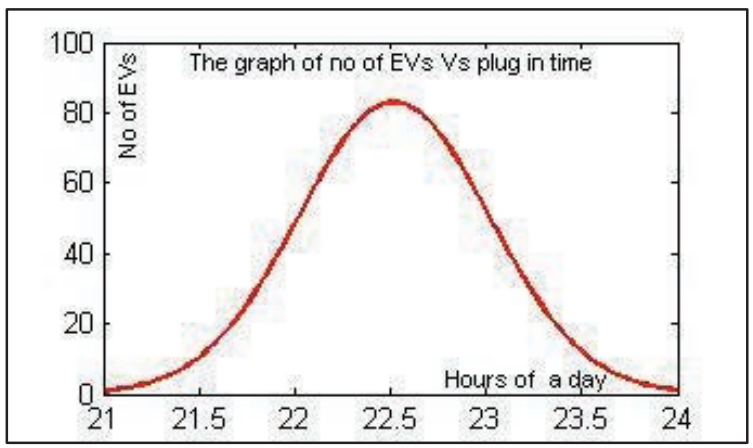

Figure $2 b$ - Graph of No. of EVs with TOU $(\mu=2230$ and $\sigma=0.5)$

Figures $2 \mathrm{a}$ and $2 \mathrm{~b}$ show the random number distribution of 1000 EVs for the two plug in times.

$>$ Generation of a set of uniformly distributed random numbers for the EV charge durations. (probability density curve of charge duration vs. No. of EVs). This study assumed that to get fully charged, an EV battery required $3 \mathrm{~kW}$ for 8 hours and thus the average charge durations were considered as 2, 3, 4, 5 and $6 \mathrm{hrs}$. 


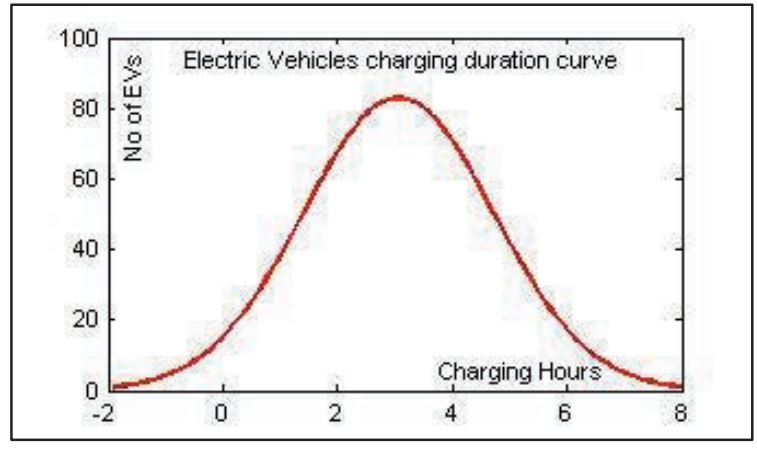

Figure 3a - Charge duration for 3 hours

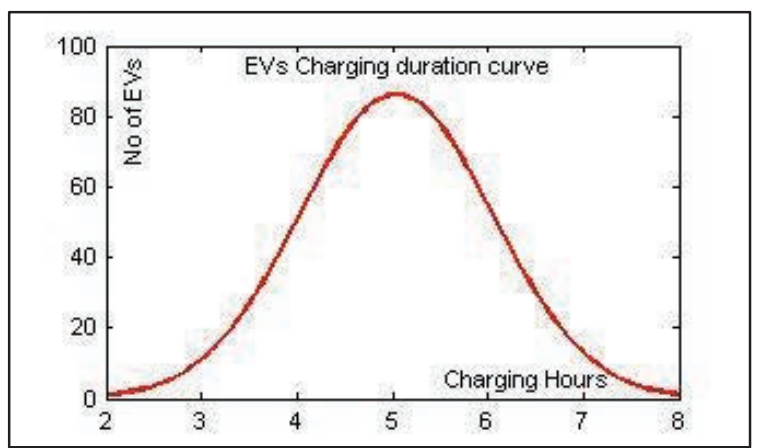

Figure $3 b$ - Charge duration for 5 hours

Figures $3 \mathrm{a}$ and $3 \mathrm{~b}$ show the probability distributions of EV charge duration for 1000 EVs for a duration of 3 and 5 hours respectively. A fully discharged battery of an EV will require up to $8 \mathrm{hrs}$. to get fully charged since the charging time will also depend on the battery state of charge. Therefore, the $\mathrm{X}$-axis of each of the two graphs was limited to $8 \mathrm{hrs}$.

\subsection{EV Battery State of Charge}

In practice, the battery state of charge (SOC) also has a strong impact on the EV charge profile. The battery SOC of an EV can be estimated from the PEV commute distance, energy efficiency which is based on the driver's behaviour, traffic conditions, climatic conditions etc. However, the study assumed that all the EVs that were considered used $\mathrm{Li}$ ion batteries each with a capacity of $24 \mathrm{kWh}$.

\subsection{EV Charge Profile}

The total charge profile of each EV was first computed individually based on the arrival time, energy requirement, and charging method. The first row in Table 3 shows the types of charging methods considered in this study, as well as the charging power and charging time of a fully discharged $24 \mathrm{kWh} \mathrm{Li}-$ ion battery.
Table 3 - Charge duration data (Source: 2014 LEAF owners' manual)

\begin{tabular}{|c|c|c|}
\hline $\begin{array}{c}\text { Charge } \\
\text { method }\end{array}$ & $\begin{array}{c}\text { Charging } \\
\text { voltage }\end{array}$ & $\begin{array}{c}\text { Charging time } \\
\text { for an empty } \\
24 \text { kWh battery }\end{array}$ \\
\hline $\begin{array}{c}\text { Level 1 } \\
\text { (Normal) }\end{array}$ & $220-240 \mathrm{~V}$ & $\begin{array}{c}\text { Approximately } \\
4-7 \text { hrs. }\end{array}$ \\
\hline $\begin{array}{c}\text { Level 2 } \\
\text { (Trickle) }\end{array}$ & $110-120 \mathrm{~V}$ & $\begin{array}{c}\text { Approximately } \\
21 \text { hrs. }\end{array}$ \\
\hline $\begin{array}{c}\text { Level 3 } \\
\text { (Quick) }\end{array}$ & $\begin{array}{c}\text { Public charging } \\
\text { station }\end{array}$ & $\begin{array}{c}\text { Approximately } \\
30 \text { min }\end{array}$ \\
\hline
\end{tabular}

If an EV commences charging in the last few hours of the day, it's end time is likely to go beyond $0000 \mathrm{hrs}$. In the circumstances, this portion of the charge profile will move to the initial hours of the next day.

\subsection{Customer Load Profile}

The daily total load variation obtained from the System Control Branch of the Ceylon Electricity Board is shown in Figure 4. The data is provided hourly for both weekdays and weekends.

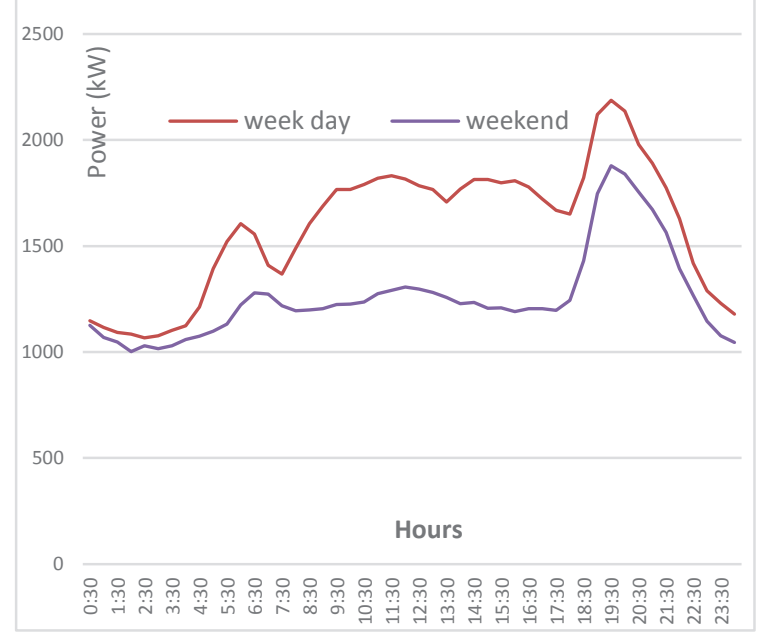

Figure 4 - Daily load profiles of Sri Lanka

When the two load curves shown in Figure 4 are compared, it can be observed that both week-day and week-end loads start decreasing at $2030 \mathrm{hrs}$. It can also be observed that the loads between $2230 \mathrm{hrs}$. and $0630 \mathrm{hrs}$. ( $8 \mathrm{hrs}$.) on a weekday are below the $1500 \mathrm{MW}$ bench mark and that they are still less during the weekend .

\section{Test Results and Analysis}

The plug in times and charge durations of the EVs had to be considered as random variables. Furthermore, because of uncertainty, distributions of random variables five in 
number had to be considered. In all cases, the parameters of the distributions were such that they all had different means and variances. However, all the distributions were based on the fact that $3 \mathrm{~kW}$ of power were required by each EV during the charging period [8]. The total power of each EV after adding the transmission and distribution losses would be more than $10.85 \%$ of the required $3 \mathrm{~kW}$. Therefore, the total charging power required by an EV can be considered as $3.325 \mathrm{~kW}$. The expected daily power demand of a typical EV could be probabilistically predicted. However, in the total distribution, the power demand will differ from one another. This gives us a useful insight into the expected charging power demands of EVs throughout the day. Here, 1000, 3000, 5000, 10000, 25000, 50000 and 100000 EVs were considered for a scheduling horizon set for a 24 hour interval [6, 7].

For a better analysis, as described in Section 2.4, two mean times for the plug-in times were considered. The demand profiles of the two plug in times had five different patterns depending on the charge durations since charging times differ from EV to EV. In the absence of realistic figures, it was reasonable to assume that the EV driving behaviour and the battery state of charge are indirectly linked to some degree. Therefore, the average battery charge durations were considered to be 2, 3, 4, 5 and $6 \mathrm{hrs}$. The standard deviation of the random number distribution was calculated for the confidence level of the distribution (i.e. $99.7 \%$ of the data were within three standard deviations $(\mu+3 \sigma)$ of the mean).

Mean $\left(\mu_{1}\right)=2$, standard deviation $\left(\sigma_{1}\right)=2$

Mean $\left(\mu_{2}\right)=3$, standard deviation $\left(\sigma_{2}\right)=1.67$

Mean $\left(\mu_{3}\right)=4$, standard deviation $\left(\sigma_{3}\right)=1.33$

Mean $\left(\mu_{4}\right)=5$, standard deviation $\left(\sigma_{4}\right)=1$

Mean $\left(\mu_{5}\right)=6$, standard deviation $\left(\sigma_{5}\right)=0.67$

Five sets of EV charge demand curves were produced for the two plug-in times using the above mentioned values of the means and the standard deviations.

\subsection{EV Charge Profile (without TOU)}

Figures 5 and 6 show the EV load profiles for $1000 \mathrm{EVs}$ at $1900 \mathrm{hrs}$. for a plug-in time and battery charge duration of $3 \mathrm{hrs}$. and $4 \mathrm{hrs}$. respectively.
Mean $\left(\mu_{2}\right)=3$, standard deviation $\left(\sigma_{2}\right)=1.67$

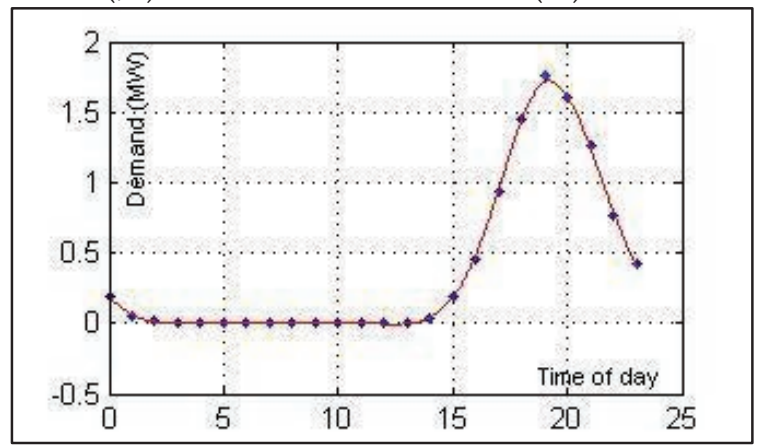

Figure 5 - EV load profile for charge duration of $3 \mathrm{hrs}$.

Mean $\left(\mu_{3}\right)=4$, standard deviation $\left(\sigma_{3}\right)=1.33$

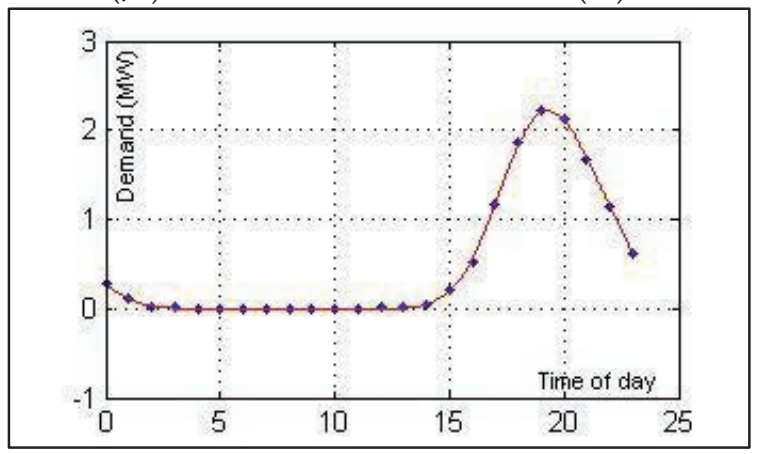

Figure 6 - EV load profile for a charge duration of $4 \mathrm{hrs}$.

\subsection{Charge Demand Curves (without TOU) of all EVs Combined}

Table 4 - EV charge demand data (MW)

\begin{tabular}{|c|c|c|c|c|c|}
\hline \multirow{2}{*}{$\begin{array}{c}\text { Time } \\
\text { (hrs. })\end{array}$} & \multicolumn{5}{|c|}{ Charge Duration } \\
\cline { 2 - 6 } & $\mu=2$ & $\mu=3$ & $\mu=4$ & $\mu=5$ & $\mu=6$ \\
\hline 1 & 0.0864 & 0.1929 & 0.3258 & 0.6817 & 1.3435 \\
\hline 2 & 0.0366 & 0.0698 & 0.0864 & 0.2859 & 0.7249 \\
\hline 3 & 0.0133 & 0.0266 & 0.0166 & 0.1230 & 0.272 \\
\hline 4 & 0 & 0.0099 & 0.0067 & 0.0333 & 0.0964 \\
\hline 5 & 0 & 0 & 0 & 0.0066 & 0.0133 \\
\hline 6 & 0 & 0 & 0 & 0 & 0.0066 \\
\hline $7-13$ & 0 & 0 & 0 & 0 & 0 \\
\hline 14 & 0.0067 & 0.0066 & 0.0033 & 0.0033 & 0.0166 \\
\hline 15 & 0.0432 & 0.0432 & 0.0498 & 0.0732 & 0.0598 \\
\hline 16 & 0.1330 & 0.1962 & 0.1729 & 0.2427 & 0.2195 \\
\hline 17 & 0.3824 & 0.5288 & 0.5221 & 0.5886 & 0.5786 \\
\hline 18 & 0.8081 & 1.1041 & 1.2404 & 1.2936 & 1.3102 \\
\hline 19 & 1.2570 & 1.6062 & 1.992 & 2.002 & 2.0485 \\
\hline 20 & 1.4599 & 1.8822 & 2.4675 & 2.5906 & 2.6604 \\
\hline 21 & 1.3202 & 1.7193 & 2.4708 & 2.7602 & 2.9630 \\
\hline 22 & 0.8546 & 1.3335 & 1.9521 & 2.5207 & 2.9829 \\
\hline 23 & 0.4755 & 0.9212 & 1.3102 & 2.012 & 2.6338 \\
\hline 24 & 0.2228 & 0.4289 & 0.7516 & 1.3268 & 2.0152 \\
\hline
\end{tabular}




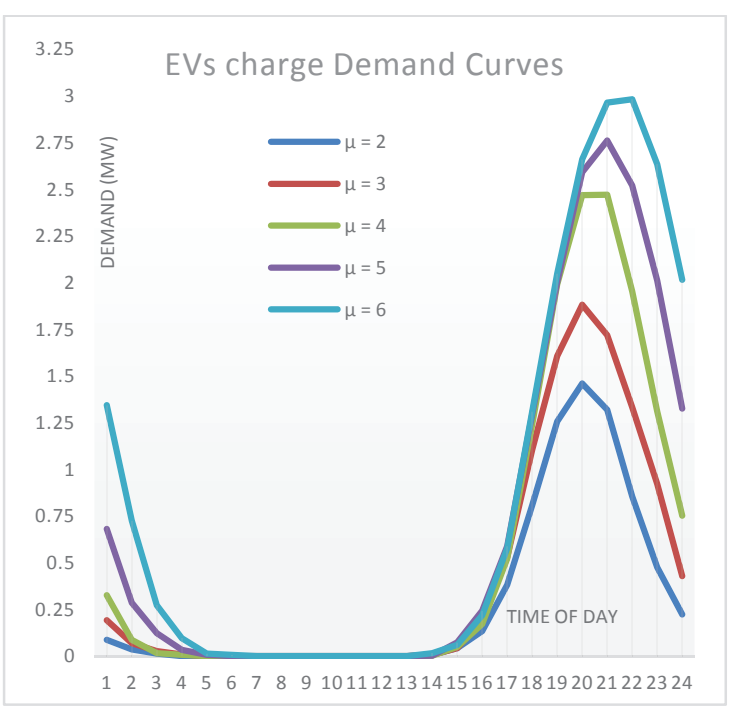

Figure 7 - EV charge demand curves (without TOU)

Figure 7 shows five different demand curves for $1000 \mathrm{EVs}$ with different charge durations. Plug-in time was considered as $1900 \mathrm{hrs}$.

\subsection{Daily Demand Curves (without TOU)}

Total Demand $=[$ Normal daily load profile + EV charge loads for different hours of charge durations $(\mu=2,3,4,5,6)$ ]

Table 5 - Total demand values for different charge durations

\begin{tabular}{|c|c|c|c|c|r|}
\hline \multirow{2}{*}{$\begin{array}{c}\text { Time } \\
\text { (hrs. })\end{array}$} & \multicolumn{5}{|c|}{ Total Demand (MW) } \\
\hline 1 & 1116.687 & 1116.793 & 1116.926 & 1117.282 & 1117.944 \\
\hline 2 & 1085.137 & 1085.17 & 1085.187 & 1085.386 & 1085.825 \\
\hline 3 & 1075.813 & 1075.827 & 1075.817 & 1075.923 & 1076.073 \\
\hline 4 & 1124.7 & 1124.71 & 1124.707 & 1124.733 & 1124.79 \\
\hline 5 & 1392.2 & 1392.2 & 1392.2 & 1392.207 & 1392.213 \\
\hline 6 & 1606.3 & 1606.3 & 1606.3 & 1606.3 & 1606.307 \\
\hline 7 & 1408.8 & 1408.8 & 1408.8 & 1408.8 & 1408.8 \\
\hline 8 & 1490.1 & 1490.1 & 1490.1 & 1490.1 & 1490.1 \\
\hline 9 & 1687.1 & 1687.1 & 1687.1 & 1687.1 & 1687.1 \\
\hline 10 & 1767.3 & 1767.3 & 1767.3 & 1767.3 & 1767.3 \\
\hline 11 & 1820.4 & 1820.4 & 1820.4 & 1820.4 & 1820.4 \\
\hline 12 & 1814.9 & 1814.9 & 1814.9 & 1814.9 & 1814.9 \\
\hline 13 & 1767 & 1767 & 1767 & 1767 & 1767 \\
\hline 14 & 1769.007 & 1769.007 & 1769.003 & 1769.003 & 1769.016 \\
\hline 15 & 1813.543 & 1813.543 & 1813.55 & 1813.573 & 1813.56 \\
\hline 16 & 1808.433 & 1808.497 & 1808.473 & 1808.543 & 1808.52 \\
\hline 17 & 1721.182 & 1721.329 & 1721.322 & 1721.389 & 1721.378 \\
\hline 18 & 1650.908 & 1651.204 & 1651.340 & 1651.394 & 1651.410 \\
\hline 19 & 2120.957 & 2121.306 & 2121.692 & 2121.702 & 2121.748 \\
\hline 20 & 2137.856 & 2138.282 & 2138.868 & 2138.991 & 2139.060 \\
\hline 21 & 1891.220 & 1891.619 & 1892.371 & 1892.660 & 1892.863 \\
\hline 22 & 1630.255 & 1630.734 & 1631.352 & 1631.921 & 1632.383 \\
\hline 23 & 1288.776 & 1289.22 & 1289.61 & 1290.312 & 1290.934 \\
\hline 24 & 1179.723 & 1179.93 & 1180.252 & 1180.827 & 1181.516 \\
\hline & & & & & \\
\hline
\end{tabular}

Table 6 - EV charge demand data

\begin{tabular}{|c|c|c|c|c|c|}
\hline \multirow{2}{*}{$\begin{array}{c}\text { Time } \\
\text { (hrs.) }\end{array}$} & \multicolumn{5}{|c|}{ Charge Duration } \\
\cline { 2 - 6 } & $\mu=2$ & $\mu=3$ & $\mu=4$ & $\mu=5$ & $\mu=6$ \\
\hline 1 & 1.1439 & 1.7126 & 2.7003 & 3.1758 & 3.3221 \\
\hline 2 & 0.6384 & 0.9377 & 1.6428 & 2.7269 & 3.2822 \\
\hline 3 & 0.2394 & 0.3891 & 0.6152 & 1.6361 & 2.8067 \\
\hline 4 & 0.076 & 0.1030 & 0.133 & 0.6651 & 1.6228 \\
\hline 5 & 0.0133 & 0.0099 & 0.0099 & 0.1463 & 0.4423 \\
\hline 6 & 0.0033 & 0.0033 & 0 & 0.0133 & 0.0399 \\
\hline 7 & 0 & 0 & 0 & 0 & 0.0033 \\
\hline $8-20$ & 0 & 0 & 0 & 0 & 0 \\
\hline 21 & 0.0599 & 0.0532 & 0.0565 & 0.0499 & 0.0964 \\
\hline 22 & 1.2936 & 1.5197 & 1.7458 & 1.5496 & 1.7891 \\
\hline 23 & 2.2846 & 2.9298 & 3.2623 & 3.2556 & 3.202 \\
\hline 24 & 1.7525 & 2.4242 & 3.2190 & 3.2988 & 3.322 \\
\hline \multicolumn{7}{|c|}{}
\end{tabular}

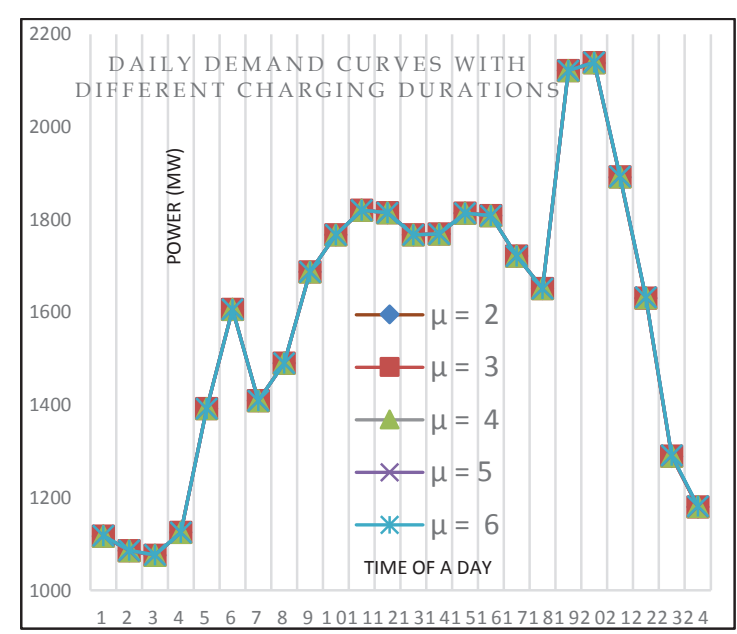

Figure 8 - Daily demand profiles for different charge durations

Figure 8 shows the normal daily demand curve for different charge durations superimposed on 1000 numbers of EV loads plugged in 1900 hrs. mean time (worst case scenario). Note that all of the charge duration curves are falling in line since 1000 EVs will not have much of an impact.

\subsection{EV Charge Profile (with TOU)}

Figures 9 and 10 show the EV load profiles for 1000 EVs with the plug-in time at $2230 \mathrm{hrs}$. and with a battery charge duration of $2 \mathrm{hrs}$. and 4 hrs. respectively.

Mean $\left(\mu_{1}\right)=2$, standard deviation $\left(\sigma_{1}\right)=2$

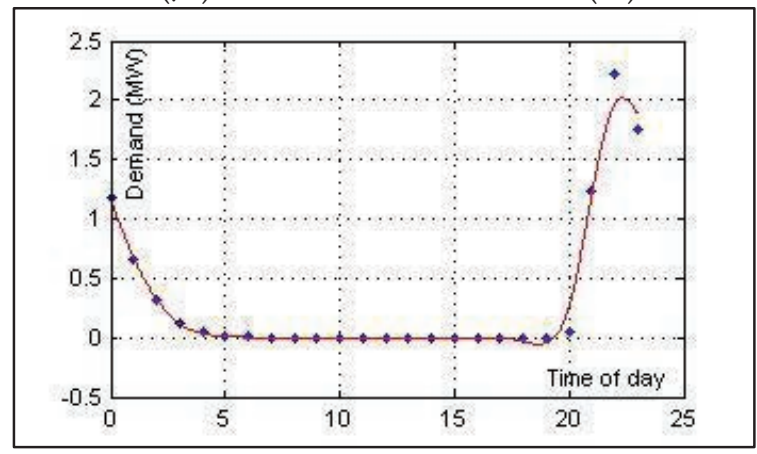

Figure 9 - EV load profile for a charge duration of 2 hrs 
Mean $\left(\mu_{3}\right)=4$, standard deviation $\left(\sigma_{3}\right)=1.33$

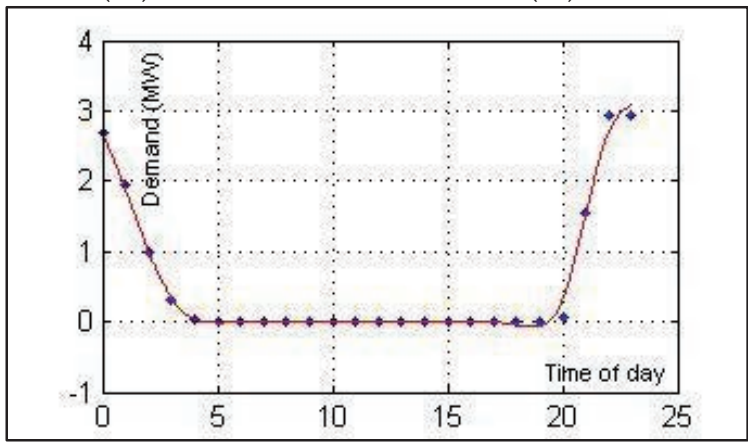

Figure 10 - EV load profile for a charge duration of 4 hrs

3.5 EV charge demand curves (with TOU) combined

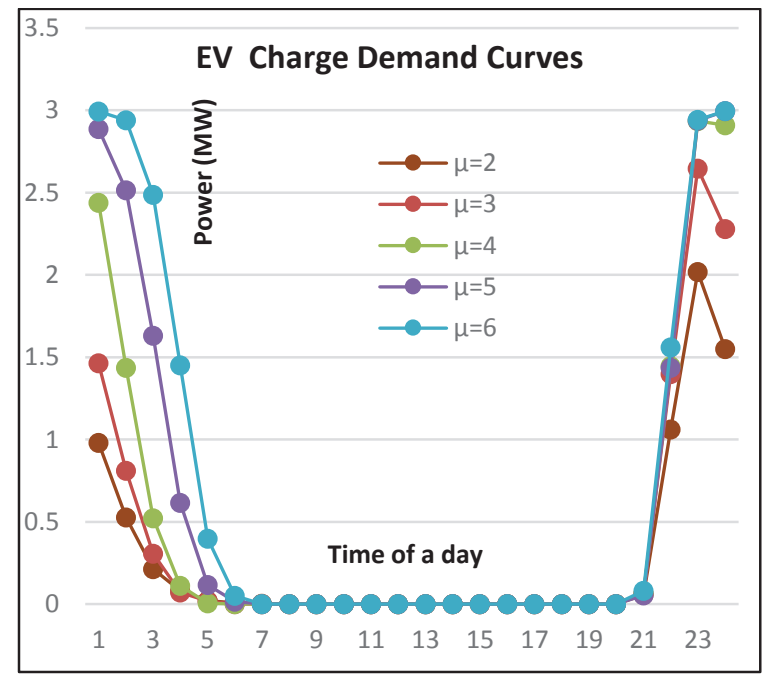

Figure 11 - EV charge demand (with TOU)

The chart in Figure 11 shows EV charge demand profiles for different charge durations.

3.6 Total Demand Curves (with TOU)

Total Demand $=[$ Normal Daily Load Profile + EVs Charging loads with different charging durations. $(\mu=2,3,4,5,6)]$

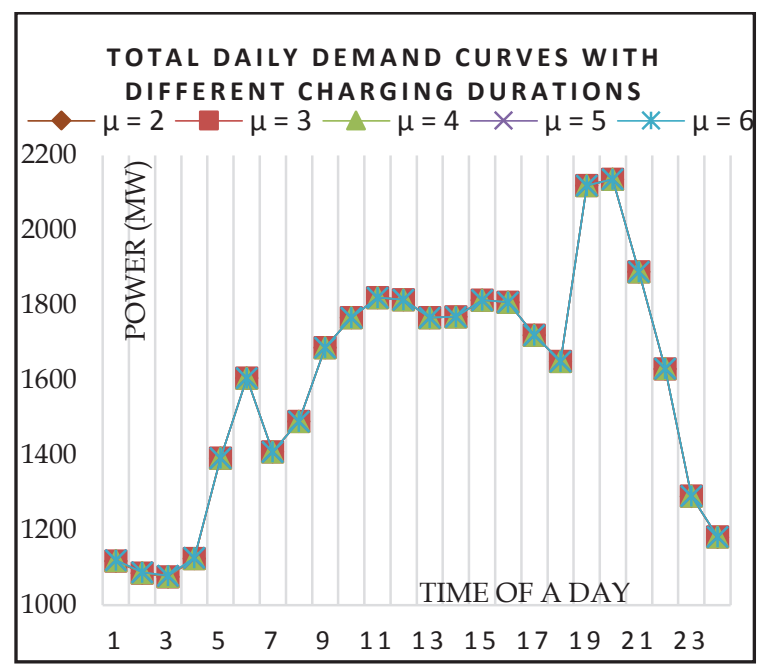

Figure 12 - Total daily demand curves for different charge durations
Table 7 - Total demand values for different charge durations

\begin{tabular}{|c|c|c|c|c|c|}
\hline \multirow{2}{*}{$\begin{array}{c}\text { Time } \\
\text { (hrs.) }\end{array}$} & \multicolumn{5}{|c|}{ Total Demand $(\mathrm{MW})$} \\
\cline { 2 - 6 } & 1117.74 & 1118.313 & 1119.3 & 1119.776 & 1119.922 \\
\hline 2 & 1085.73 & 1086.038 & 1086.743 & 1087.827 & 1088.382 \\
\hline 3 & 1076.03 & 1076.189 & 1076.415 & 1077.436 & 1078.607 \\
\hline 4 & 1124.78 & 1124.803 & 1124.833 & 1125.365 & 1126.323 \\
\hline 5 & 1392.21 & 1392.21 & 1392.21 & 1392.346 & 1392.642 \\
\hline 6 & 1606.30 & 1606.303 & 1606.3 & 1606.313 & 1606.34 \\
\hline 7 & 1408.8 & 1408.8 & 1408.8 & 1408.8 & 1408.803 \\
\hline 8 & 1490.1 & 1490.1 & 1490.1 & 1490.1 & 1490.1 \\
\hline 9 & 1687.1 & 1687.1 & 1687.1 & 1687.1 & 1687.1 \\
\hline 10 & 1767.3 & 1767.3 & 1767.3 & 1767.3 & 1767.3 \\
\hline 11 & 1820.4 & 1820.4 & 1820.4 & 1820.4 & 1820.4 \\
\hline 12 & 1814.9 & 1814.9 & 1814.9 & 1814.9 & 1814.9 \\
\hline 13 & 1767 & 1767 & 1767 & 1767 & 1767 \\
\hline 14 & 1769 & 1769 & 1769 & 1769 & 1769 \\
\hline 15 & 1813.5 & 1813.5 & 1813.5 & 1813.5 & 1813.5 \\
\hline 16 & 1808.3 & 1808.3 & 1808.3 & 1808.3 & 1808.3 \\
\hline 17 & 1720.8 & 1720.8 & 1720.8 & 1720.8 & 1720.8 \\
\hline 18 & 1650.1 & 1650.1 & 1650.1 & 1650.1 & 1650.1 \\
\hline 19 & 2119.7 & 2119.7 & 2119.7 & 2119.7 & 2119.7 \\
\hline 20 & 2136.4 & 2136.4 & 2136.4 & 2136.4 & 2136.4 \\
\hline 21 & 1889.96 & 1889.953 & 1889.957 & 1889.95 & 1889.996 \\
\hline 22 & 1630.694 & 1630.92 & 1631.146 & 1630.95 & 1631.189 \\
\hline 23 & 1290.585 & 1291.23 & 1291.562 & 1291.556 & 1291.502 \\
\hline 24 & 1181.253 & 1181.924 & 1182.719 & 1182.799 & 1182.822 \\
\hline & & & & & \\
\hline 1
\end{tabular}

Figure 12 shows the normal daily demand curve superimposed on the $1000 \mathrm{EV}$ charge loads for different charge durations. Since the vehicle number is small, the charge duration curves fall in line and are not significantly visible.

\subsection{Total Demand Curves for Different Numbers of Vehicles}

The EV loads and their consumption behaviours can be controlled with the introduction of the TOU by PUSL. Since EV loads will depend on the number of vehicles, different numbers of EVs were then considered to ascertain the sensitivity of their impact. The number of EVs was taken as 1000, 3000, $5000,10000,25000,50000$ and 100000 with an average battery charge duration of $5 \mathrm{hrs}$. to make it simple. 
Table 8 - EV demand (without TOU) in MW

\begin{tabular}{|c|c|c|c|c|c|c|c|}
\hline $\begin{array}{c}\text { Time } \\
\text { (hrs.) }\end{array}$ & 1000 & 3000 & 5000 & 10000 & 25000 & 50000 & 100000 \\
\hline 1 & 0.681 & 2.045 & 3.552 & 7.246 & 18.067 & 36.015 & 72.236 \\
\hline 2 & 0.306 & 0.938 & 1.506 & 3.163 & 7.947 & 15.998 & 31.239 \\
\hline 3 & 0.096 & 0.329 & 0.489 & 1.014 & 2.710 & 5.507 & 11.233 \\
\hline 4 & 0.027 & 0.096 & 0.14 & 0.263 & 0.721 & 1.519 & 3.039 \\
\hline 5 & 0.003 & 0.04 & 0.023 & 0.06 & 0.156 & 0.292 & 0.578 \\
\hline 6 & 0.003 & 0.007 & 0.003 & 0.01 & 0.019 & 0.059 & 0.116 \\
\hline 7 & 0 & 0.007 & 0 & 0.003 & 0.006 & 0.006 & 0.016 \\
\hline $8-9$ & 0 & 0 & 0 & 0 & 0 & 0 & 0.003 \\
\hline $10-11$ & 0 & 0 & 0 & 0 & 0 & 0 & 0 \\
\hline 12 & 0 & 0 & 0 & 0 & 0 & 0.003 & 0.013 \\
\hline 13 & 0 & 0.003 & 0.003 & 0.013 & 0.013 & 0.039 & 0.129 \\
\hline 14 & 0.013 & 0.013 & 0.023 & 0.086 & 0.202 & 0.392 & 0.907 \\
\hline 15 & 0.04 & 0.153 & 0.203 & 0.4998 & 1.230 & 2.354 & 4.768 \\
\hline 16 & 0.193 & 0.582 & 0.888 & 1.9796 & 4.838 & 9.830 & 19.447 \\
\hline 17 & 0.555 & 1.782 & 2.734 & 5.743 & 14.329 & 29.078 & 57.777 \\
\hline 18 & 1.274 & 3.824 & 6.165 & 12.384 & 31.223 & 62.047 & 124.174 \\
\hline 19 & 2.025 & 6.242 & 10.312 & 20.332 & 50.979 & 101.989 & 203.244 \\
\hline 20 & 2.704 & 7.842 & 13.232 & 26.351 & 65.801 & 131.556 & 263.841 \\
\hline 21 & 2.853 & 8.430 & 14.123 & 27.948 & 70.151 & 140.505 & 281.580 \\
\hline 22 & 2.574 & 7.599 & 12.856 & 25.586 & 63.952 & 128.218 & 256.562 \\
\hline 23 & 2.002 & 5.913 & 10.016 & 20.113 & 50.082 & 100.144 & 200.484 \\
\hline 24 & 1.300 & 3.874 & 6.488 & 13.206 & 33.098 & 66.253 & 132.717 \\
\hline
\end{tabular}

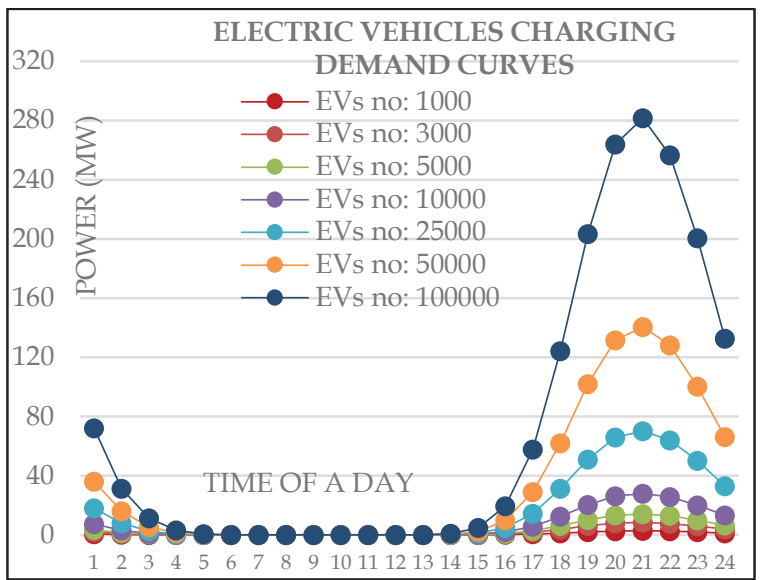

Figure 13 - EV charge demand (without TOU)

Figure 13 shows seven demand curves for a 5 hr. charge duration and for several numbers of electric vehicle loads. Plug-in time was considered as $1900 \mathrm{hrs}$.

\subsection{EV Charge Demand (with TOU)}

Table 9 - EV demand (with TOU) in MW

\begin{tabular}{|c|c|c|c|c|c|c|c|}
\hline $\begin{array}{c}\text { Time } \\
\text { (hrs) }\end{array}$ & $\begin{array}{l}\text { EV\# } \\
1000\end{array}$ & $\begin{array}{c}\text { 3000 } \\
\text { EV\# }\end{array}$ & $\begin{array}{c}\text { EV\# } \\
10000\end{array}$ & $\begin{array}{c}\text { EV\# } \\
25000\end{array}$ & $\begin{array}{c}\text { EV\# } \\
50000\end{array}$ & $\begin{array}{c}\text { EV\# } \\
100000\end{array}$ \\
\hline 1 & 3.183 & 9.567 & 15.979 & 31.938 & 79.619 & 159.454 & 318.58 \\
\hline 2 & 2.690 & 8.064 & 13.398 & 27.03 & 67.052 & 134.107 & 268.125 \\
\hline 3 & 1.726 & 5.018 & 8.327 & 16.754 & 41.402 & 83.367 & 166.102 \\
\hline 4 & 0.672 & 1.866 & 3.266 & 6.501 & 16.085 & 32.483 & 65.303 \\
\hline 5 & 0.143 & 0.359 & 0.692 & 1.284 & 3.392 & 6.9569 & 14.273 \\
\hline 6 & 0.02 & 0.03 & 0.07 & 0.11 & 0.316 & 0.698 & 1.503 \\
\hline 7 & 0 & 0 & 0.003 & 0.01 & 0.013 & 0.03 & 0.08 \\
\hline $8-19$ & 0 & 0 & 0 & 0 & 0 & 0 & 0 \\
\hline 20 & 0 & 0 & 0 & 0 & 0.00333 & 0.003 & 0.01 \\
\hline 21 & 0.08 & 0.196 & 0.343 & 0.7681 & 1.939 & 3.661 & 7.745 \\
\hline 22 & 1.69 & 4.855 & 8.360 & 16.830 & 42.048 & 83.104 & 165.617 \\
\hline 23 & 3.239 & 9.734 & 16.311 & 32.563 & 81.196 & 162.564 & 324.778 \\
\hline 24 & 3.312 & 9.92 & 16.544 & 33.132 & 82.705 & 165.494 & 331.080 \\
\hline
\end{tabular}

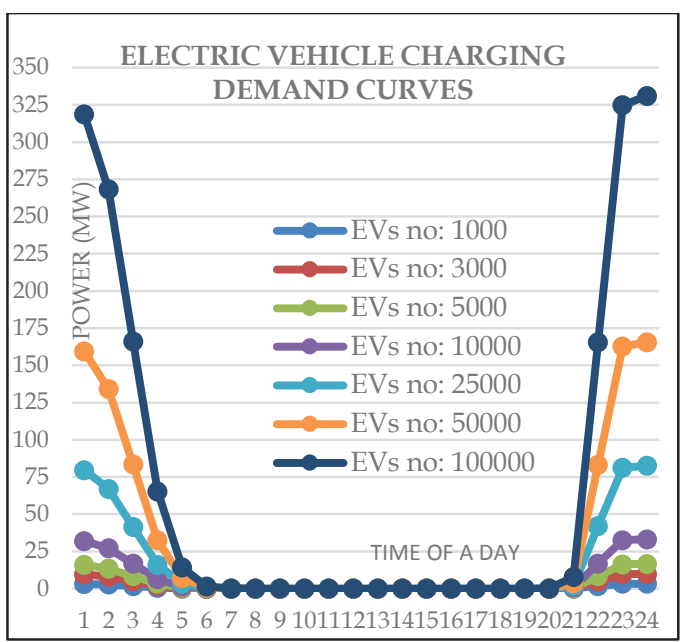

Figure 14 - EV charge demand (with TOU)

Figure 14 also gives a comparison of load profiles of different numbers of electric vehicle loads. It shows that when the number of EVs increases, the energy consumption of the EVs will also increase. The plug-in time was considered as 1900 hrs.

\subsection{Daily Demand Curve (without TOU)}

If not for the introduction of the TOU tariff, the total demand curves for different numbers of vehicle fleets would have been as shown in Figure $1 \mathrm{~A}$ of Appendix-1. It also shows that there are several peaks that occur during day time, with the highest values generally occurring in late evening, with significant spikes in the mornings and in early afternoons. All demand curves reach their peaks during the same time interval. The highest peak load is noted between 1900 hrs. and 2100 hrs. while morning spikes are found between $0500 \mathrm{hrs}$. and 0700 hrs. As can be seen from the curves in Figure 1A of Appendix-1, the contribution of EV vehicles to the peak demand would be 2.704, 7.842, 13.232, 26.351, 65.802, 131.56 and 263.6 MW for 1000, 3000, 5000, 10000, 25000 , 50000 and 100000 EVs respectively.

\subsection{Total Daily Demand Curves (with TOU)}

Figure 1B in Appendix-1 shows that the total demand profiles with the TOU tariff are generally different from one other. All demand curves reach the peak load at the same time. The highest peak load is noted between 1830 hrs. and 2130 hrs. while morning spikes are noted between 0430 hrs. and 0730 hrs. It is interesting to see that the effect on the system peak is minimal with TOU. 


\section{Conclusion}

Electric vehicles have an increasing potential in the vehicle market while issues related to energy crises are still going on. Plug-in EVs create opportunities to reduce the reliance on fossil fuels thereby lowering the operating costs. EVs can be regarded as distributed energy storage units and have a great potential to contribute to load shifting in load management. The inconclusive nature of EV charging behaviours brings in great challenges to power grid operation and peak-valley regulation. EV charging loads are mainly determined by EV types, charging durations, charging modes, and battery characteristics. The charging of a large number of EVs will have an impact on the transmission and distribution of a power system.

The total power required from the system by an EV was approximately $3.325 \mathrm{~kW}$ which included its transmission and distribution losses. The EV charge demand curves were prepared by combining the probability distribution curves of both variables, and charge demand curves were subsequently superimposed on the system load profile.

Because of its stochastic nature, the probabilistic distribution of the variables such as the number of EVs, plug-in times and battery charge durations were considered using the Monte Carlo simulation technique. The impact due to the plug-in time was considered with and without the TOU tariff structure for a better comparison. Since the EV usage in Sri Lanka is on a positive trend, if not for the TOU of electrical tariff system, the EV's charging behaviour in time to come would have a significant effect on the system demand during the peak load period. As can be seen, the proposed methodology gives an idea about the impact of EVs on the system load profile. The impact of the EV loads after the introduction of the present TOU tariff seems to be minimal.

\section{Acknowledgement}

The authors would like to offer their appreciation to Dr. Narendra de Silva and Eng. Sahan Edirisinghe of LECO, Eng. M. Lakshitha Weerasinghe of CEB and Mr. I. A. Premaratne of OUSL for the technical guidance provided.

\section{References}

1. Nanjun, L. U., Javad, L., “Electric Vehicles Charging Load Calculations Based on Monte Carlo Method", Faculty of Eng., The University of Columbia, 15 th May 2014, pp.3-8.

2. $\mathrm{Au}, \mathrm{T} . \mathrm{K}$. , "Assessment of Plug in Electric Vehicle Charging on Distribution Networks", M.Sc. in Electrical Engineering. University of Washington, 2012, pp 1-11.

3. Guo, Q., Wang, y., Sun, H., Zhengshuo Li., Xin, S., Zhang, B., "Factor Analysis of the Aggregated Electric Vehicle Load Based on Data Mining", University of Beijing, 21th June 2012, Energies 2012,5, pp 2054-2058.

4. Zeng, D., Wang, K., Yaping, Li., Xiaorui, G., Jiang, X., "Load Cluster Characteristic Analysis and Modelling of Electric Vehicles", Electric Power Research Institute, China, June 2013, pp 1-3.

5. Alonso, M., Amaris, H., Germain, J. G., Galan, J. M., "Optimal Charging Scheduling of Electric Vehicles in Smart Grids by Huristic Algorithms", Dept. of Elecrical Eng.,University of Carlo,Spain,17th April 2014,Energy 2014,7,24492456.

6. Putrus, G. A., Suwanapingakarl, P., Johnston, D., Bentley, E. C., Narayana, M., "Impact of Electric Vehicles on Power Distribution Networks", School of Eng. and Information Science, The University of Northumbria, UK, pp 1-3.

7. Hung, S., Infield, D., "The potential of Domestic Electric Vehicles to Contribute to Power System Operation through Vehicle to Grid Technology", Dept. of Electronic \& Electrical Engineering, The University of Strachclycle, UK.

8. Huang, S., Infield, D.," The Impact of Domestic Plug-in Hybrid Electric Vehicles on Power Distribution System Loads", Dept. of Electronic Electrical Eng., University of Strathclyde, UK. IEEE.

9. Taylor, J., Maitra, A., Alexander, M., Brooks, D., Duvall, M., "Evaluation of The Impact of Plug in Electric Vehicle. Loading on Distribution System Operation", pp 1-4

10. Rosell P., Robels R.V., Sumper A., Jane J.B., "Probabilistic Agent Based Model of Electric Vehicle Charging Demand to Analysis the Impact on Distribution Network", 11 th May 2015, Energies 2015,8, pp 4160-4172. 
Appendix-1

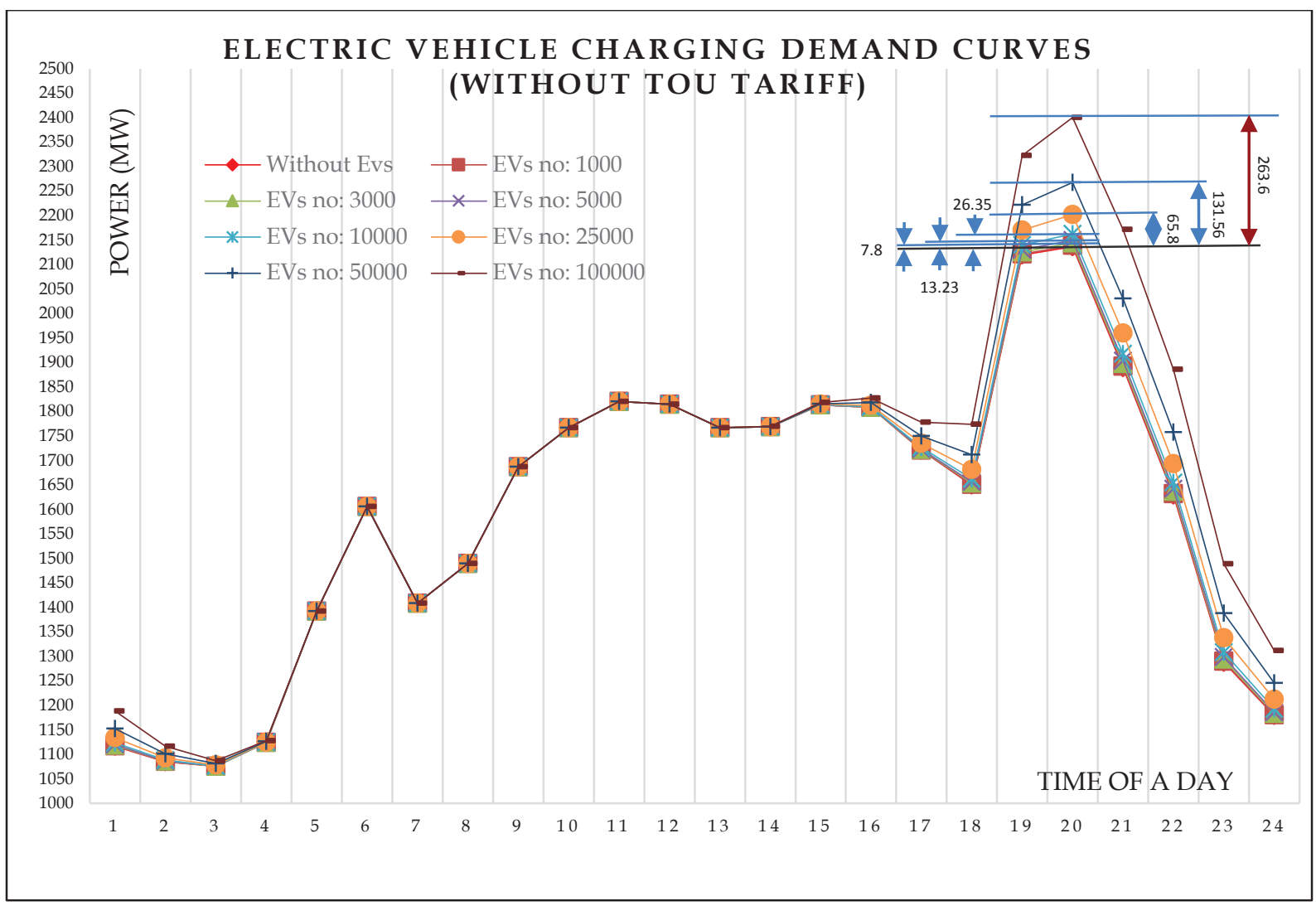

Figure 1A - EV charge demand curves for different number of EVs (without TOU tariff)

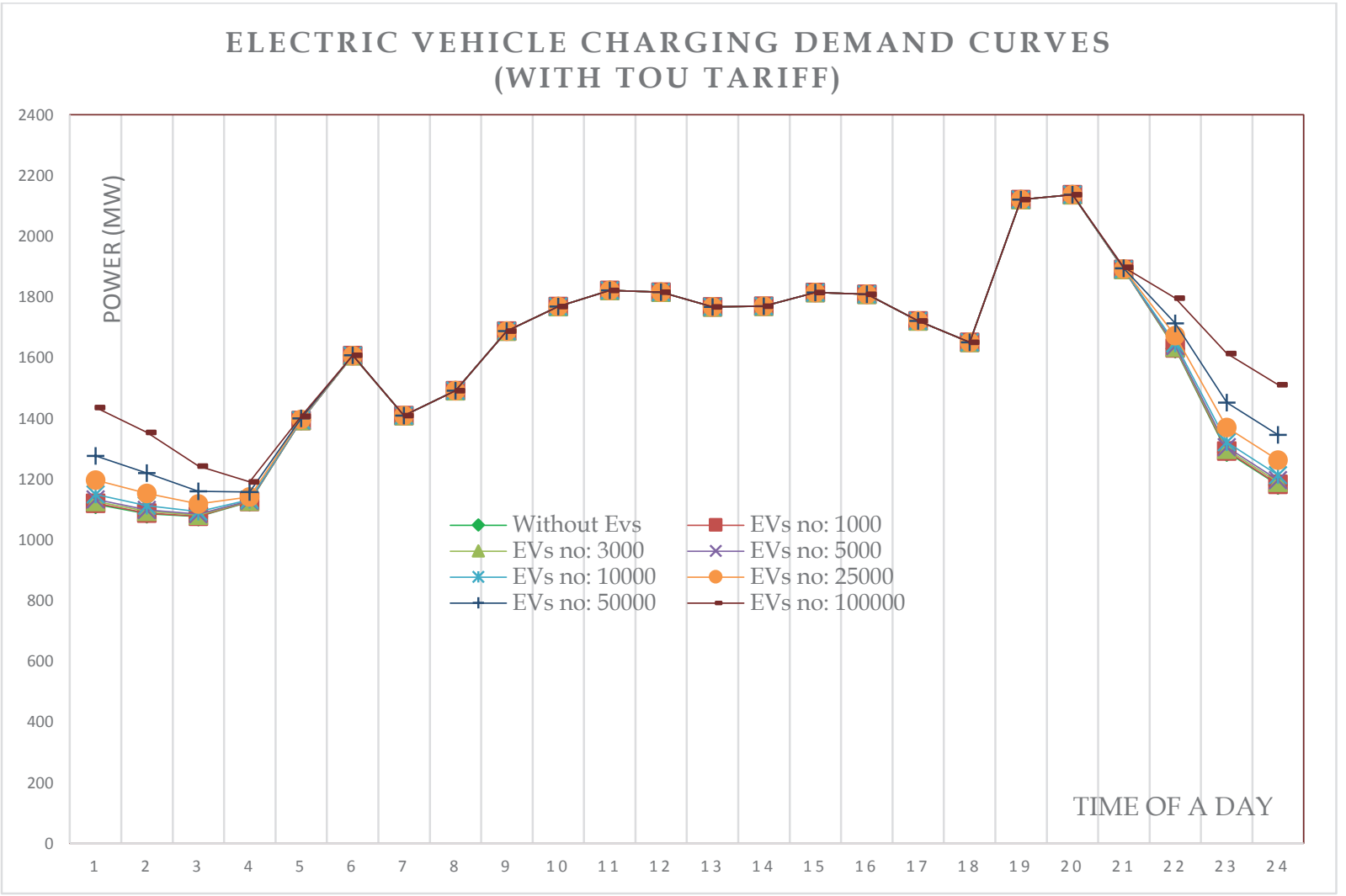

Figure 1B - EV charge demand curves for different number of EVs (with TOU tariff) 